\title{
Victimization in the U.S. Military: The Impact of Labeling Events on Officially Reporting Sexual
}

\section{Harassment}

\author{
Richard J. Harris (Corresponding author) \\ Department of Social Work \\ University of Texas at San Antonio \\ 501 West Durango Blvd \\ San Antonio, Texas, 78207, U.S.A.
}

Tel: (210)458-2843 FAX: (210) 458-3001Ｅ-mail: Richard.Harris@utsa.edu

\author{
Juanita M. Firestone \\ Department of Criminal Justice \\ University of Texas at San Antonio \\ 501 West Durango Blvd \\ San Antonio, Texas, 78207, U.S.A.
}

Tel: (210) 458-2830 FAX: (210) 458-2633Ｅ-mail: Juanita.Firestone@utsa.edu

\begin{abstract}
We analyzed the extent to which type and labeling of harassment have an impact on reporting through official channels. Reinforcing earlier analyses, type of harassment impacted whether individuals reported incidents officially. Environmental harassment was far more likely to be reported through official channels. We speculate that "individualized" forms of harassment (personal, frequently directly physical in nature, leaving little room for misinterpretation by the victim or the perpetrator) may create a negative organizational image and therefore be more likely to be concealed. Since experiencing environmental harassment is strongly related to experiencing individualized harassment and is more likely to be reported through official channels, it may be the real key to creating zero-tolerance for any type of sexual harassment.
\end{abstract}

Keywords: Victimization, Sexual Harassment, Environmental Harassment, Individualized Harassment, Reporting Harassment, U. S. Military 


\section{Introduction}

Three basic theoretical perspectives have been used to understand sexual harassment. The biological perspective suggests that men and women are naturally attracted to each other and that in order to maximize their reproductive potential, males should engage in sexually aggressive behaviors because if their advances are accepted they increase the likelihood of creating offspring (Tangri \& Hayes, 1997). Women, on the other hand, have a higher investment in reproduction and nurturing their offspring and would be less likely to behave in sexually aggressive ways (Tangri \& Hayes, 1997). Thus a situation becomes defined as harassment only if the woman is not receptive to the sexual behavior (Tangri \& Hayes, 1997). The socio-cultural perspective focuses on differential sex role socialization of men and women (Firestone \& Harris, 1994; Tangri \& Hayes, 1997; Terpstra \& Baker, 1986; Whatley \& Wasieleski, 2001). Sexual harassment is consistent with the socially accepted roles of dominant and aggressive men and submissive and subordinate women (this also helps explain the reluctance to believe that men are harassed).

The organizational perspective focuses on individual power - those with more power can (and often do) make harassing demands on those with less power (Terpstra \& Baker, 1986). Research indicates that most harassment is perpetrated by co-workers rather than superiors (Firestone \& Harris, 1994; 1999) which seems inconsistent with this perspective. However, as Thacker (1996) notes, individuals with less organizational status may display power through their personalities or by controlling critical information; thus harassment may appear to be less threatening to observers when perpetrated by co-workers but may appear equally severe to targets.

One reason for the continued extent of harassment may be the problems associated with reporting incidences. A number of myths about sexual harassment reinforce difficulties in reporting, particularly within formal organizational systems. These myths are similar to those that prevent reporting rape, and reflect a tendency to blame the victim. One such myth is that victims "ask for it" by their behavior and/or dress. Sexual harassment is not experienced only by young, "attractive" women. Studies show that sexual harassment threatens all women, and some men, regardless of age, race, marital status, or appearance (Grauerholz, 1996; Siegal, 1991). Another myth is that women often make false claims of sexual harassment, especially if they are angry with a man for personal reasons. Another myth focuses on the belief that sexual harassment is predicated on mutual desire, consensual sexual teasing, love, attraction or affection between individuals. These latter myths arise out of stereotypical gender role attitudes defining sexual harassment as the "normal" outcome of the "natural" attraction between men and women (Tangri \& Hayes, 1997). This explanation implies that sexual harassment is an individual behavior, ignoring organizational norms and policies that may create, reinforce or emphasize such behavior as acceptable (Firestone and Harris, 1999; Williams, 1997). Thus, within organizational contexts sexual harassment often reflects differences in power as well as the ability to dominate and humiliate others (Colatosti \& Karg, 1991; DiTomaso, 1989; Paetzold \& O’Leary-Kelly, 1996; Terpstra \& Baker, 1986).

The continued prevalence of these and similar myths suggests that implementing policies to 
provide a non-threatening procedure for filing official complaints may be particularly important (Firestone \&Harris, 1994; 1997; 1999; Whatley \& Wasieleski, 2001). To be effective, policies must be designed and implemented in such a way as to insure that those experiencing harassment do not believe they are being held responsible for their own victimization (Gruber \& Bjorn, 1986; Hulin, Fitzgerald \& Drasgow, 1996; MacKinnon, 1989; Riger, 1991). For example Balogh, Kite, Pickel, Canel, \& Schroeder (2003) noted that timing of reporting impacts others' perceptions about reporting an incidence. Targets who postpone reporting are more likely to be viewed negatively and as having ulterior motives in reporting. This ignores the fact that policies and implementations create and support the work climate in which targets perceive whether or not complaints will be taken seriously, which can also affect the timing of reporting.

Unfortunately, policy implementation in the past has often implicitly accepted the correctness of many of the myths. For example, the individual who complained of harassment was frequently fired, demoted or transferred while the harasser typically remained at the same job during what can be a lengthy investigation. Furthermore, fear of being blamed (either for the harassment or for filing charges against the perpetrator) may prevent many women from labeling a behavior as harassment, which, in turn, may discourage using official channels to report incidents. Thus, often only those who are not afraid of being labeled a "troublemaker" are likely to identify experiences as sexual harassment and, as a result, report them (Malovich \& Stake, 1990; Stockdale \& Vaux, 1993; Saal, 1996; Thomas, 1995). Interestingly, research suggests that personal assertiveness was the strongest predictor of reporting sexual harassment through formal channels (Adams-Roy and Barling, 1998). Women who behave in personally assertive ways are often classified as overly aggressive or in other denigrating ways. This further contributes to lack of reporting through official channels. Finally, as Williams (1997) points out, some behaviors that could be legally defined as sexual harassment can actually be a condition of employment, which reduces substantially the likelihood of complaints (see also, Guiffre \& Williams, 1994)?

There are a variety of responses to sexual harassment, which range from ignoring the situation to directly confronting the harasser to filing formal complaints. Previous research suggests that personal rather than formal responses to harassment are the norm, regardless of work climate, or even the nature of the harassment (Firestone \& Harris, 1997; Fain \& Anderton, 1987; Livingston, 1982; Terpstra, 1986; Grauerholz, 1989; Bingham \& Scherer, 1993; see also McAllister, 1996). Interestingly some research suggests that women who reported sexual harassment through formal channels manifested lower perceptions of procedural justice relative to their organizational context (Adams-Roy \& Barling, 1998). Whatley \& Wasieleski (2002) indicated that response choices differed by sex of target; males favored more "active" responses (e.g., threatening to report the perpetrator or contacting the perpetrator's spouse), and females were more likely to use passive responses (e.g., ignoring the behavior or avoiding the perpetrator). Importantly, in neither case did the targets choose to report the incident through official channels (Whatley \& Wasieleski, 2002). While personal responses are most typical in all situations, the type of harassment experienced, individualized or environmental, may directly affect whether the response is formal or 
informal in nature. As conceptualized by Firestone \& Harris (1994), individualized harassment includes behaviors that leave little room for misinterpretation and are frequently physical in nature (e.g., actual or attempted rape, uninvited or unwanted pressure for sexual favors or dates, touching, leaning over, cornering, pinching), while environmental harassment refers to a broader organizational context of sexist behaviors (e.g., unwanted and uninvited letters, phone calls, sexually suggestive looks/gestures/body language, calls/hoots/yells of a sexual nature).

Baker, Terpstra \& Larntz (1990) found that sexually coercive experiences (like demanding sexual favors or dates, or touching) were more likely to be reported than more general harassment (like sexual teasing, jokes and whistles). Fitzgerald, Swan \& Fischer (1995) argued that a victim's response relates to her or his need to reduce personal stress. If changing the situation is the preferred result, then individuals are more likely to report the problem through official channels, while ignoring the harassment or joking about it are used when the desired outcome is to reduce the victim's stress level. In previous work, Firestone \& Harris (1997) discovered that environmental harassment was more likely to elicit personal rather than institutional responses from targets, and that individualized harassment, while less likely to be reported, was more likely to elicit an institutional response. Welsh \& Gruber (1999) found that reporting was more prevalent based on severity of the harassment as well as when a supervisor or multiple harassers perpetrated the event. In contrast, Bingham \& Scherer (1993) found that type of harassment had no significant impact on reporting the incident(s). All of the above studies confirm that clearly defining the situation as harassment, with no uncertainty possible, is important in predicting type of response. In other words, people are likely to take stronger actions when they are certain that the situation will be perceived as sexual harassment by others (Bingham 1991; Balough et al. 2003).

Our research analyzes the impact of environmental and individual harassment on labeling an event as harassment as well as their impact along with labeling harassment on reporting through official channels. In combination, previous research suggests that the type of harassment experienced may impact whether the target labels the event as harassment which, in turn, impacts whether the event is reported through official channels. Figure 1 presents a conceptual model of the proposed relationships. 


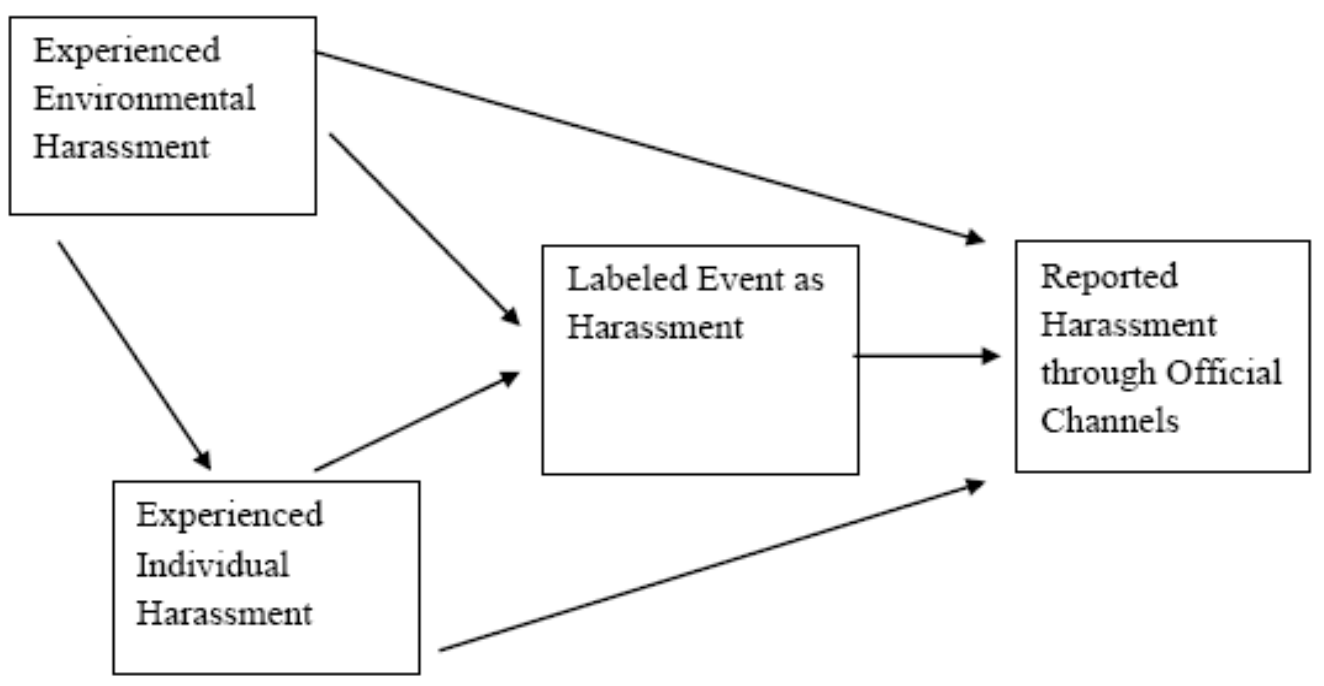

Figure 1. Conceptual Model of Relationships among Experiencing Environmental or Individual Harassment, Labeling it as Harassment and Reporting through Official Channels

\section{Methods}

Our research examines a sample of respondents from the "Armed Forces 2002 Sexual Harassment Survey" (Lipari and Lancaster, 2003) conducted for the Office of the Secretary of Defense by the Defense Manpower Data Center. This was a "worldwide scientific survey of how men and women work together in the ... Active-duty Military Services ..." The stated purpose of the survey was " [t]o assess the prevalence of sexual harassment and other unprofessional, gender-related behaviors..." (Lipari and Lancaster, 2003, p. 6). The instrument "was based on the 1995 Form B questionnaire and incorporated further psychometric and theoretical advances in sexual harassment research" (Lipari and Lancaster, 2003. p. 6). The military organization provides a useful context for testing our model, as members represent a good cross-section of the adult population in the U.S. In addition the military context is built on a tradition of stereotypical gender role and male bonding norms. As part of this process, cohesion is an important part of defining group solidarity. This process has been used to exclude rather than include women because women are thought to intrude on male bonding (solidarity). Sexual harassment can be used as a covert means to continue to resist the acceptance of women as soldiers. Thus, the military cultural norms may produce a workplace that is hostile to women and reinforce environmental types of sexual harassment, which in turn reinforce the individualized and more personal forms of harassment (Firestone and Harris, 1994).

\subsection{Sample}

A single-stage, stratified random sample of 60,415 respondents was drawn for the survey, representing male and female enlisted personnel and officers in the Army, Navy, Marines, Air Force and Coast Guard. Data were collected by mail and via the Web, with one-third of respondents returning responses via the internet. An introductory letter was mailed to those 
selected into the sample six weeks prior to the arrival of the questionnaire packet containing instructions for answering and the survey document. A thank you letter for responding or a reminder with another survey packet was mailed out four months and 8 months after the initial survey attempt. A total of 19,960 usable surveys were returned for a response rate of 36 \% (see, Flores-Cervantes, Valiant, Harding and Bell, 2003). A 36\% response rate is not unusual for a mailed (or internet) survey. Keeter, Miller, Kohut, Groves, and Presser (2000) after systematic analysis of two telephone surveys, one with a $36 \%$ response rate and one with a $60 \%$ response rate, found very few statistically significant differences between estimates from the two surveys. Thus, the effect of non-response on survey estimates is not judged as critical (Fowler, 2002, p. 44). The un-weighted final sample includes 10,235 males and 9,725 females, illustrating the oversampling of women (for descriptive information about variables, see Firestone and Harris (1999). The sampling frame was stratified by service branch, sex, paygrade, race/ethnicity, likelihood of deployment and geographic location (Elig, 2003). A series of weighting schemes was developed by the original survey team at the Defense Manpower Data Center tied to branch of service, rank, sex and race, and to test for non-response bias. The full weights provide estimated numbers of respondents that approximate the total active force as of December 2001 (Lipari and Lancaster 2003: 5). While the survey documentation provides no information about a specific IRB review board, all surveys conducted by the Department of Defense are reviewed by the relevant military units.

\subsection{Analysis}

For the analyses that follow, the full weight was divided by the mean weight, retaining estimates of the approximate total number of cases in the original survey. This adjustment is useful for making tests of statistical significance more appropriate. In this analysis, a cross-tabulation is used to describe the relationship between labeling an incident as harassment and reporting it through official channels for men and for women. Logistic regression is used to test whether labeling an event as sexual harassment impacts the likelihood of reporting various forms of harassment and discrimination based on sex. In addition we investigate whether men or women, different race and ethnic groups, and /or different ranks are more or less likely to label an event as sexual harassment (see Tables 1 and 2). Logistic coefficients, odds ratios or predicted probabilities cannot answer, in a comparative sense, how strong is the effect of a particular independent variable (Kaufman, 1996; Long, 1987; Menard, 2002).

Addressing these issues requires a reference point (standard of comparison) for measuring the magnitude of the association, and a standard frame of reference for measuring differences in the independent variables. To solve this problem we initially use the $r$ statistic as a measure of strength of relationship. (Note 1) Then, to enable us to use the logic of path analysis, we calculated standardized predicted logit $(\ddot{Y})$ coefficients to determine a comparative framework for assessing the comparative effects of the independent variables on reporting harassment through official channels (Kaufman 1996; Long 1987; Menard 2002). Appendix A provides the calculations used to produce the standardized predicted logit coefficients which we used to standardize effects for comparative purposes in our analysis. While these standardized coefficients cannot be used to numerically calculate indirect effects, they can be used as a 
heuristic to show how the mediation of effects operates (e.g., X1 has not only a direct effect but also operates indirectly by how it affects Y1 which then affects Y2).

We expect findings to support past research indicating that when targets label events as sexual harassment they are more likely to take steps to prevent them from occurring again. Additionally, we expect environmental harassment to be more likely than individualized experiences to be reported through official channels.

\subsection{Variable Construction}

Among the items in the "Gender Related Experiences in the Military in the Past 12 Months" section of the survey, respondents were asked the following:

In this question you are asked about sex/gender related talk and/or behavior that was unwanted, uninvited, and in which you did not participate willingly.

How often during the past 12 months have you been in situations involving

- $\quad$ Military Personnel

- $\quad$ On- or off-duty

- $\quad$ On-or off installations or ship; and/or

- $\quad$ Civilian Employees and/or Contractors

- $\quad$ In your workplace or on your installation/ship

Where one or more of these individuals (of either gender)...

Respondents were then provided a list of 19 items and asked whether that item had occurred "very often," “often," "sometimes," "once or twice," or "never." These variables are of course highly skewed. We recoded the first four responses in an "ever" occurred category with a value of 1 . "Never" was coded 0 . Based on the original statements, we identified individualistic forms of sexual harassment that are personal and frequently directly physical in nature, and leave little room for misinterpretation by either the victim or the perpetrator (sexual assault, touching, sexual phone calls; 11 items, Cronbach's alpha $=0.83$ ). This form can be differentiated from a broader category of more public, environmental harassment (jokes, whistles, suggestive looks; five items, Cronbach's alpha $=0.73$ ). The latter actions can be experienced even if directed at another individual, and are ambiguous enough to leave their interpretation dependent on the environmental context. (Note 2) Respondents were initially classified as having experienced individualistic or environmental unwanted, uninvited sexual behavior, or any form, (individualistic, environmental, or both). We focus on the separate categories of environmental and individual harassment for this research.

Respondents were then asked whether they considered "ANY of the behaviors... which YOU MARKED AS HAPPENING TO YOU ... to have been sexual harassment [emphases part of original survey]". Responses included "none were sexual harassment," some were sexual harassment; some were not sexual harassment," and "all were sexual harassment." This variable was dichotomized to indicate whether "any" events were labeled as sexual 
harassment, or none were labeled as harassment. Another question asked "Did you report this situation to any of the following installation/Service/DoD individuals or organizations.” The responses included references to the various official channels for reporting. Individuals who responded "yes" to any of the categories were classified as having used official channels to report the incident. Independent variables utilized include sex of respondent, rank (junior enlisted, senior enlisted, junior officer, senior officer), whether respondent was married, and service branch.

\section{Results}

Perhaps most telling is that among men only 3.53\% experienced harassment and then reported it through any official channel, while among women $15.87 \%$ experienced and reported through some official channel.

Table 1. through Relationship Between Labeling Sexual Harassment and Reporting Official Channels by Sex of Respondent

\begin{tabular}{|c|c|c|c|c|}
\hline & \multirow[b]{2}{*}{$\begin{array}{c}\text { No } \\
\text { Experience }\end{array}$} & \multicolumn{2}{|c|}{ Labeled Harassment } & \multirow[b]{2}{*}{ Total } \\
\hline & & $\begin{array}{c}\text { None } \\
\text { Labeled }\end{array}$ & $\begin{array}{c}\text { Some } \\
\text { Labeled }\end{array}$ & \\
\hline \multicolumn{5}{|l|}{ Male } \\
\hline No Harassment/No Report & 100.00 & 86.54 & 72.84 & 96.47 \\
\hline Some Official Report & & 13.46 & 27.16 & 3.53 \\
\hline Total & 100.00 & 100.00 & 100.00 & 100.00 \\
\hline $\mathrm{N}$ & 12484 & 3113 & 556 & 16153 \\
\hline \multicolumn{5}{|l|}{ Female } \\
\hline No Harassment/No Report & 100.00 & 79.10 & 62.14 & 84.13 \\
\hline Some Official Report & & 20.90 & 37.86 & 15.87 \\
\hline Total & 100.00 & 100.00 & 100.00 & 100.00 \\
\hline $\mathrm{N}$ & 1327 & 804 & 774 & 2905 \\
\hline
\end{tabular}

Dependent Variable: Reported Harassment through Official Channels

*Source: DoD IG Report D-2000-101

As shown in Table 1, those men who experienced harassment and labeled incidents as such were over twice as likely to report the incident(s) through official channels. Only about $13 \%$ of men who did not label an incident as harassment reported it through official channels, compared to $27.2 \%$ of those filing official reports when incident was labeled. The relationship also holds true for women. Only $20.9 \%$ of women who did not label the incident as sexual harassment filed charges through official channels, compared to $37.86 \%$ of women who did label the incident as harassment. 
Table 2. Logistic Regression Coefficients Associated with Reporting through Official Channels, Controlling for Marital Status, Branch, and Rank

Panel A: Complete Sample

\begin{tabular}{|c|c|c|c|c|c|c|c|}
\hline & B & $\begin{array}{l}\text { Std. } \\
\text { Error }\end{array}$ & Wald & df & Sig. & $\operatorname{Exp}(B)$ & $\begin{array}{c}\text { R } \\
\text { statistic }\end{array}$ \\
\hline (Constant) & -5.08 & 0.44 & 130.65 & 1 & 0.00 & 0.01 & \\
\hline Individual & 0.81 & 0.09 & 84.07 & 1 & 0.00 & 2.26 & 0.12 \\
\hline \multicolumn{8}{|l|}{ Harassment } \\
\hline \multicolumn{8}{|l|}{ Harassment } \\
\hline Female & 0.70 & 0.08 & 75.49 & 1 & 0.00 & 2.01 & 0.11 \\
\hline Married & 0.22 & 0.08 & 7.93 & 1 & 0.01 & 1.24 & 0.03 \\
\hline Army & 0.12 & 0.10 & 1.68 & 1 & 0.20 & 1.13 & 0.00 \\
\hline Navy & 0.15 & 0.10 & 2.23 & 1 & 0.14 & 1.16 & 0.01 \\
\hline Marines & -0.05 & 0.14 & 0.14 & 1 & 0.13 & 0.95 & 0.00 \\
\hline Coast Guard & 0.38 & 0.21 & 3.07 & 1 & 0.08 & 1.46 & 0.01 \\
\hline Junior Enlisted & 0.45 & 0.43 & 1.11 & 1 & 0.29 & 1.58 & 0.00 \\
\hline Senior Enlisted & 0.27 & 0.43 & 0.39 & 1 & 0.53 & 1.31 & 0.00 \\
\hline Junior Officer & 0.05 & 0.45 & 0.01 & 1 & 0.91 & 1.05 & 0.00 \\
\hline Senior Officer & 0.17 & 0.46 & 0.13 & 1 & 0.72 & 1.18 & 0.00 \\
\hline Labeled as & 0.83 & 0.09 & 85.99 & 1 & 0.00 & 2.30 & 0.12 \\
\hline \multicolumn{8}{|l|}{ Harassment } \\
\hline $\begin{array}{l}\text { Nagelkerke Adjusted } \\
\mathbf{R}^{2}\end{array}$ & 0.31 & & & & & & \\
\hline
\end{tabular}

Dependent Variable: Reported Harassment through Official Channels

*Source: DoD IG Report D-2000-101

Table 2 displays results for logistic regression analyses measuring the impacts of type of harassment (individual compared to environmental) and labeling the event as harassment on reporting the incident through official channels, with controls for other contextual variables found to be important in previous research (Firestone and Harris, 1994; 1997; 1999; 2003). Panel A present results predicting likelihood of filing an official report after controlling for type of harassment, labeling the incident as harassment, sex of respondent, marital status, service branch and rank. The model explains just over 30\% of the likelihood of reporting through official channels (Nagelkerke $\mathrm{R}^{2}=.31$ ). (Note 3) Among the significant predictors, experiencing environmental harassment has the strongest impact, with those respondents seven times more likely to file official reports. Labeling the incident as harassment has the second strongest impact with experiencing individual harassment next in importance. Sex of respondent had the next most important impact, with women being twice as likely as men to report through official channels. Both labeling and sex of respondent more than double the likelihood of reporting through official channels. Being married was the weakest of the significant predictors. Those who were married were slightly more likely to report incidents through official channels. 
Table 2 (continued). Logistic Regression Coefficients Associated with Reporting through Official Channels, Controlling for Marital Status, Branch, and Rank

\section{B}

PANEL B: Females

(Constant)

Individual

Harassment

Environmental

Harassment

Married

Army

Navy

Marines

Coast Guard

Junior Enlisted

Senior Enlisted

Junior Officer

Senior Officer

Labeled as

Harassment

Nagelkerke Adj. $\mathbf{R}^{2}$

PANEL C: Males

(Constant)
Individual
Harassment

Harassment

Married

Army

Navy

Marines

Coast Guard

Junior Enlisted

Senior Enlisted

Junior Officer

Senior Officer

Labeled as

Harassment

\section{Std. \\ Error}

Wald

df

$-5.60$

0.53

111.47

0.11

66.85

0.13

359.90

0.11

10.00

0.13

2.69

0.14

2.17

0.00

0.17

4.84

0.25

1.37

0.28

0.51

0.05

0.54

0.02

0.55

45.62

0.81

0.12

0.24

$-3.39$

0.84

16.09

0.15

17.78

1
1

0.00

0.03

0.00

1.87

0.09

1.09

0.16

46.68

0.00

2.96

0.14

\subsection{2}

0.12

1.03

0.31

1.12

0.00

0.03

0.14

0.05

0.82

1.03

0.00

0.17

0.15

1.22

0.27

1.18

0.00

$-0.05$

0.26

0.04

0.84

0.95

0.00

0.05

0.41

0.02

0.90

1.06

0.00

0.19

0.83

0.05

0.82

1.21

0.00

0.20

0.83

0.06

0.82

1.22

0.00

$-0.10$

0.85

0.01

0.91

0.91

0.00

0.20

0.87

0.05

0.82

1.22

0.00

1.06

0.14

59.58

0.00

2.89

Nagelkerke Adj. R2

0.27

Dependent Variable: Reported Harassment through Official Channels

*Source: DoD IG Report D-2000-101 
The results from the separate models for women and men containing additional controls are similar to the original results, with slight changes in the importance of the individual variables (see Table 2, Panels B and C). Among women, after introducing the full set of control variables, labeling the incident as harassment had the strongest impact on likelihood of using official channels, with experiencing environmental harassment as the second strongest, and experiencing individual harassment as the third strongest impact. Being married had no significant impact on using official channels for women. Among men, experiencing environmental harassment had the strongest impact, followed by experiencing individual harassment and then by labeling the incident as harassment. Being married was a significant predictor of reporting through official channels for men, although it had the weakest impact. Finally, being in the Coast Guard shows a significant though small increase in the likelihood of filing an official report. Overall the model explains slightly more of the likelihood of filing official charges for men than for women (Nagelkerke $\mathrm{R}^{2}=.24$ for women; .27 for men).

The number of non-significant variables evident in the models presented in Table 2, Panel A suggest a more parsimonious approach to the analysis. This simpler approach also lends itself to the conceptualized path analysis sequence for the models. Interestingly comparing the results for men and women reveals different patterns. Among men, experiencing environmental harassment was the strongest predictor of filing an official report, with experiencing individual harassment having the second strongest impact. Labeling the incident was the weakest among these predictors, although men who labeled the incident as harassment were still more than twice as likely to report the incident officially.

Among women, labeling the incident as harassment was the strongest predictor of filing an official report, with experiencing environmental harassment the second strongest predictor, and experiencing individual harassment the weakest predictor among this set. Based on the Nagelkerke $\mathrm{R}^{2}$, this simple model is slightly better at predicting men's likelihood of filing an official report than women's (Nagelkerke $\mathrm{R}^{2}=.27$ for men; $\mathrm{R}^{2}=.24$ for women).

The $\mathrm{R}^{2}$ values in Table 3 are the same as the ones in Table 2, illustrating that the more parsimonious models have the same explanatory power as the full model. In Table 3, Panel A displays the results for all respondents, controlling for sex, while Panel B presents results only for Females and Panel C only for Males. Those experiencing environmental harassment were more than seven times as likely to officially report the incident. Labeling an incident as sexual harassment was the second strongest predictor, followed closely by experiencing individual harassment. Both labeling and individual harassment were over twice as likely to lead to an official report. Finally women were almost twice as likely as men to report the incident, after controlling for type of harassment and labeling the incident. 
Table 3. Logistic Regression Coefficients for the Impacts of Type of Sexual Harassment and Labeling of Incidents on Reporting through Official Channels

\begin{tabular}{|c|c|c|c|c|c|c|c|}
\hline & B & $\begin{array}{l}\text { Std. } \\
\text { Error }\end{array}$ & Wald & df & Sig. & $\operatorname{Exp}(B)$ & $\begin{array}{c}\text { R } \\
\text { statistic }\end{array}$ \\
\hline \multicolumn{8}{|l|}{ Panel A: Complete Sample } \\
\hline (Constant) & -4.54 & 0.08 & 3475.02 & 1 & 0.00 & 0.01 & \\
\hline Individual Harassment & 0.83 & 0.09 & 92.14 & 1 & 0.00 & 2.29 & 0.12 \\
\hline Environmental Harassment & 1.97 & 0.10 & 409.25 & 1 & 0.00 & 7.20 & 0.26 \\
\hline Sex of Respondent & 0.67 & 0.08 & 72.31 & 1 & 0.00 & 1.96 & 0.11 \\
\hline Labeled as Harassment & 0.86 & 0.09 & 92.96 & 1 & 0.00 & 2.36 & 0.12 \\
\hline Nagalkerke Adjusted $R^{2}$ & 0.27 & & & & & & \\
\hline \multicolumn{8}{|l|}{ Panel B: Females } \\
\hline (Constant) & -3.10 & 0.12 & 661.59 & 1 & 0.00 & 0.05 & \\
\hline Individual Harassment & 0.63 & 0.14 & 18.91 & 1 & 0.00 & 1.87 & 0.07 \\
\hline Environmental Harassment & 1.08 & 0.16 & 46.90 & 1 & 0.00 & 2.94 & 0.11 \\
\hline Labeled as Harassment & 1.07 & 0.14 & 61.37 & 1 & 0.00 & 2.90 & 0.13 \\
\hline Nagelkerke Adjusted $\mathbf{R}^{2}$ & 0.24 & & & & & & \\
\hline \multicolumn{8}{|l|}{ Panel C: Males } \\
\hline (Constant) & -4.87 & 0.10 & 2413.83 & 1 & 0.00 & 0.01 & \\
\hline Individual Harassment & 0.90 & 0.11 & 72.97 & 1 & 0.00 & 2.47 & 0.18 \\
\hline Environmental Harassment & 2.37 & 0.12 & 364.64 & 1 & 0.00 & 10.71 & 0.41 \\
\hline Labeled as Harassment & 0.85 & 0.12 & 50.91 & 1 & 0.00 & 2.34 & 0.15 \\
\hline Nagelkerke Adjusted R2 & 0.27 & & & & & & \\
\hline
\end{tabular}

Dependent Variable: Reported Harassment through Official Channels

*Source: DoD IG Report D-2000-101

\subsection{Logistic "Path" Models}

Figure 2 presents a "path" model using the calculated standardized logistic coefficients (see Appendix A) for the total sample, and Figure 3 presents separate models for women (Panel A) and for men (Panel B).

For women the impact of environmental harassment on labeling the event has the same standardized logistic coefficient as individualized harassment when rounded to two decimal places, but at three decimal places the impact of individualized harassment (.193) is slightly stronger than for environmental (.189). While environmental harassment has the dominant effect for men, the two different forms are essentially equally important for women. This likely reflects the fact that women are more likely to experience both forms of harassment than men, and far more likely to experience environmental harassment (see Figure 2). 


\section{Macrothink}

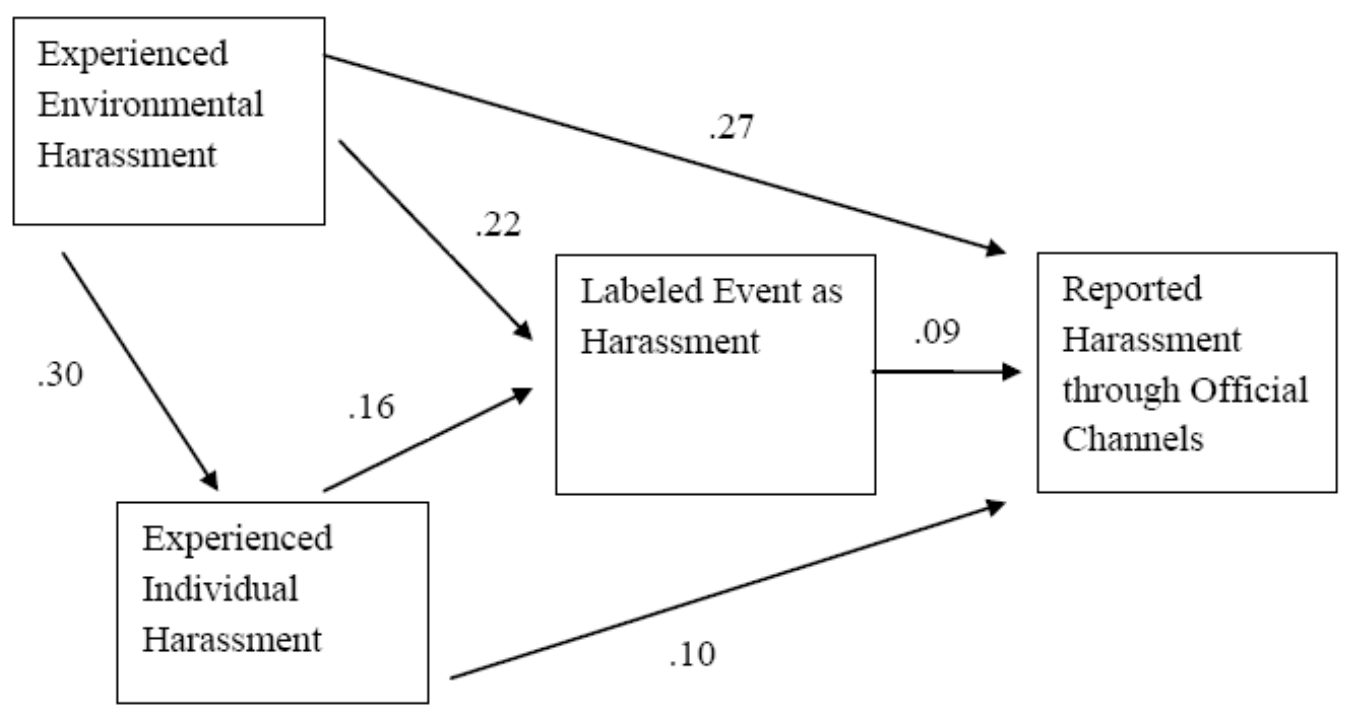

Figure 2. Relationships among Experiencing Environmental or Individual Harassment, Labeling it as Harassment and Reporting through Official Channels (Total Sample)

Importantly, after identifying likely indirect effects, for the total sample as well as for the separate samples for men and for women, experiencing environmental harassment remains the strongest impact for labeling an event as harassment for men and for the total sample and for reporting the harassment through official channels for all groups (see, Figure 3, also see Appendix A). 


\section{Panel A: Females}

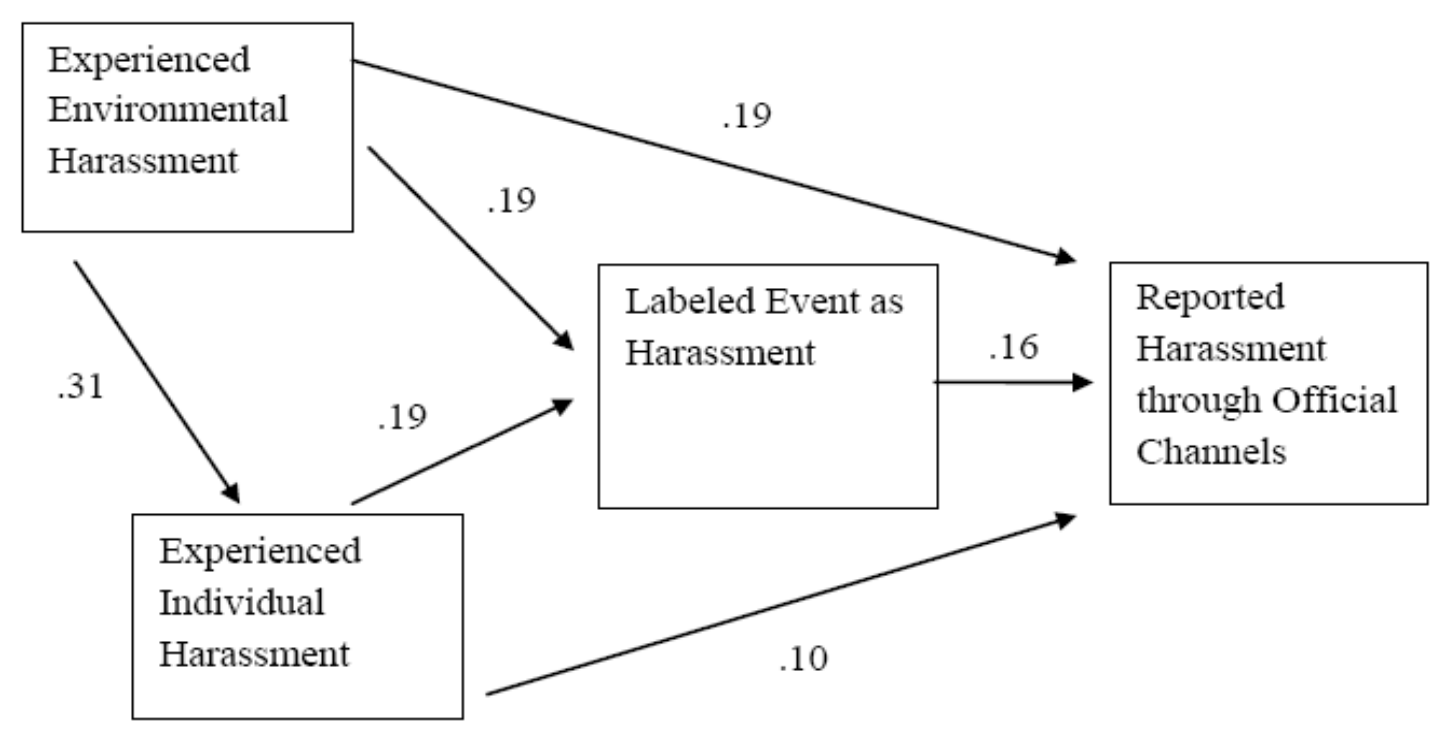

\section{Panel B: Males}

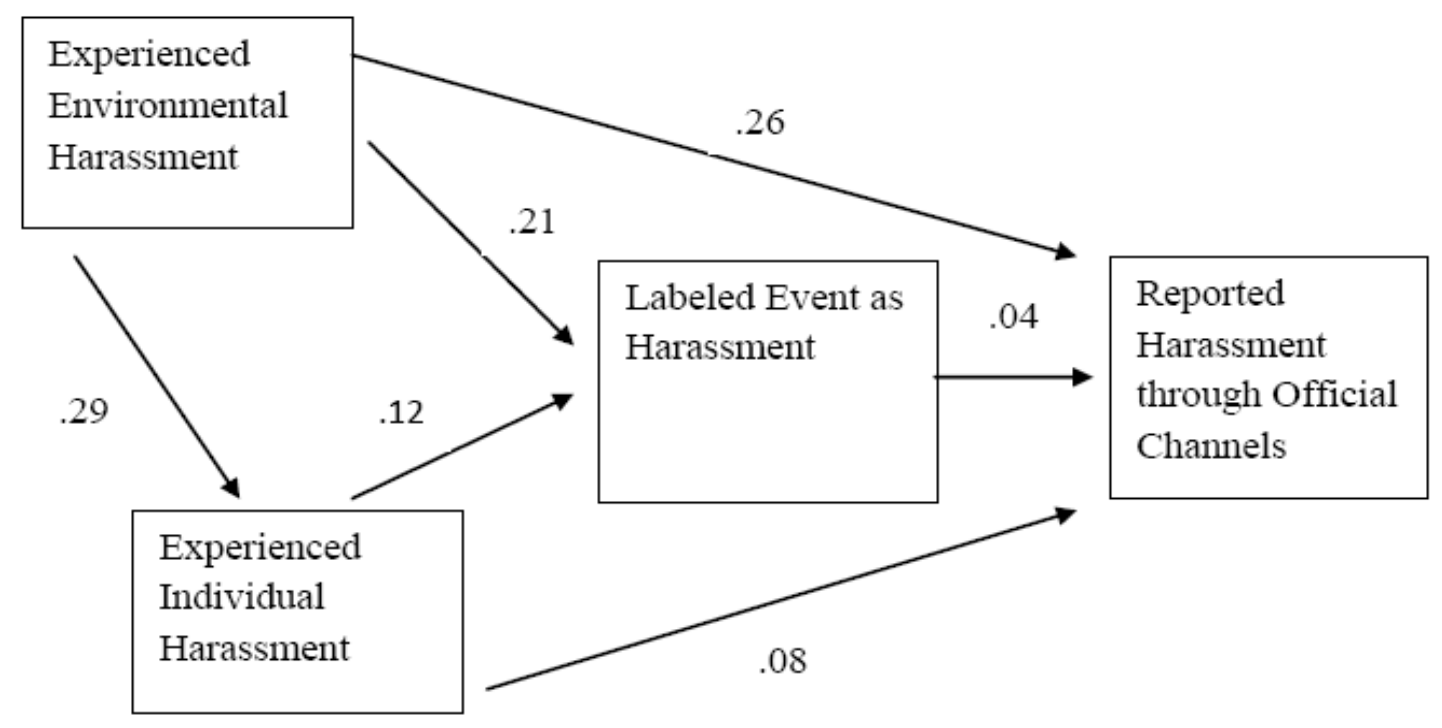

Figure 3. Relationships among Experiencing Environmental or Individual Harassment, Labeling it as Harassment and Reporting through Official Channels (Females and Males Separately)

\section{Discussion}

Data from a survey mailed to active duty members of all branches of the military were analyzed. The sample was drawn by the Department of Defense research team from a list of all DoD personnel at the time of the survey. The response rate of $36 \%$ is consistent with that of large mail surveys. Our results suggest that type of harassment has an important impact on whether individuals use official channels to report incidents. Those who say they experience 
environmental harassment are far more likely to use official means of reporting incidents. While this relationship holds for both men and women, it is dramatically stronger for men ( $\mathrm{r}$ $=.31$ compared to $\mathrm{r}=.14$ for women, Table 2). It may be the case that experiencing individualized types of harassment is more likely to be associated with other types of personal threats which could lead to targets being fearful of reporting them officially. This would be exacerbated if the perpetrator were a superior who could retaliate against anyone reporting incidents, especially if it is the target's word against the superior's. Because environmental harassment often occurs in a more public setting it may be the case that it is easier to corroborate and, therefore, easier to report officially.

Worthy of note is that environmental harassment has less impact on reporting for women than for men $(\operatorname{Exp}(B)$ and $(r)$. It may be the case that because environmental harassment is seen as ambiguous enough to be dependent on context, that reporting incidents officially can leave room for a wide variety of actions from a mere "slap on the wrist" to more serious results such as demotions. Thus reports of harassment that are considered inconsequential do not make the organization look bad nor are they necessarily career-ending. In fact, such "inconsequential" incidents are more likely to reflect negatively on the individual reporting, who can become labeled a "troublemaker" or become ostracized by unit members. Thus, because women are sometimes still viewed as outsiders in military units, they may be less willing to risk being further disliked. On the other hand, accusations of "individualized" forms of sexual harassment which are personal and frequently directly physical in nature, and leave little room for misinterpretation by either the victim or the perpetrator, are likely to create a negative image of the organization and may be more likely to be concealed. A recent example of a cover-up of individualized harassment is the initial response to women attempting to file charges of sexual assault at the U.S. Military Academy at West Point.

While the full model does not increase the explanatory power over the more parsimonious model, it does provide a more nuanced understanding of some issues associated with reporting incidents through official channels. The differential impact of being married on officially reporting incidents by men and women is interesting. Perhaps the context of being married provides a backdrop for men to become more aware of and sensitive to environmental harassment. It is the case that experiencing environmental harassment increases the probability of reporting over three and a half times more for men than for women (see EXP(B)s in Tables 2 and 3).

Our findings reinforce one more time the importance of environmental harassment in understanding and eradicating sexual harassment in the U.S. military. Because policies directed at preventing or stopping sexual harassment have focused on institutional power differences alone, they may prove ineffective. The stereotypical gender norms reinforced so strongly outside the organization may interact in important ways to prevent policies focused at "defining harassment as inappropriate" (Whatley \& Wasieliski, 2001). This may be reflected in the fact that environmental harassment is far more likely to be experienced than individualized forms, and is less likely to be reported (Firestone \& Harris, 1994; 1999; 2003). Definitions of environmental harassment may be too steeped in societal definitions of what it means to be a "typical” male and female to overcome the ambiguity in clearly labeling the 
events. Both men and women want to be an accepted part of their organizational unit, however differential labels for behaviors based on the sex of the actor may inhibit individuals from defining environmental harassment as inappropriate. A better understanding of the links between accepting stereotypical gender role norms and labeling events as sexual harassment could be an important source of preventing such behaviors. It is clear that experiencing environmental harassment is strongly related to experiencing individualized harassment (Firestone \& Harris, 1994; 2003), which is more likely to be reported through official channels; therefore linking environmental harassment and stereotypical gender role ideologies may be the real key to creating an organizational climate with zero-tolerance for sexual harassment of any kind. These would be fruitful areas for further research.

\subsection{Study Limitations}

In spite of the large sample size (and very small standard errors), non-sampling errors are possible. First, because the survey was mailed under the auspices of the Department of Defense it may be the case that respondents who chose to reply were likely to give a "socially desirable” response which would underestimate harassment incidents. We do not believe an overestimate of incidents is likely because of the large percentage who did not respond to the survey, in spite of two reminders. Error could result from respondents' lack of clear recall of events which occurred during the past year, although this would be mitigated by the sensitive and critical impacts associated with harassment events. As is always the case in mailed surveys, respondents could misinterpret questions or incorrectly mark responses. However, the large sample size which produces small standard errors likely minimizes any negative impacts.

\section{References}

Adams-Roy J., \& Barling J. (1998). Predicting the decision to confront or report sexual harassment. Journal of Organizational Behavior, 19, pp.329-336.

Baker, D. D., Terpstra, D. E., \& Larntz, K. (1990). The influence of individual characteristics and severity of harassing behavior on reactions to sexual harassment. Sex Roles, 22, pp.305-325.

Balogh, D.W., Kite, M. E., Pickel, K. L., Canel, D., \& Schroeder, J. (2003). The effects of delayed report and motive for reporting on perceptions of sexual harassment. Sex Roles, 48, pp.337-348.

Bingham, S. G., \& Scherer, L L. (1993). Factors associated with responses to sexual harassment and satisfaction with outcome. Sex Roles 29, pp.239-269.

Bingham, S. G. (1991). Communication strategies for managing sexual harassment in organizations: Understanding message options and their effects. Journal of Applied Communication Research, 19, pp.88-115.

Colatosti, C., \& Karg, E. (1991). Stopping Sexual Harassment; a Handbook for Union and Workplace Activists. Detroit, MI: Labor Education and Research Project. 
DiTomaso, N. (1989). Sexuality in the workplace: Discrimination and harassment. In J. Hearn \& D. L. Sheppard (Eds.). The Sexuality of Organization, (pp. 71-90), Beverly Hills, CA: Sage.

Elig, T. W. (2003). Sampling Design for the Status of the Armed Forces Surveys - Workplace and Gender Relations (Form 2002GB), Arlington, VA: Defense Manpower Data Center.

Fain, T. C., \& Anderton, D. L. (1987). Sexual harassment: Organizational context and diffuse status. Sex Roles 17, pp. 291-311.

Firestone, J. M., \& Harris, R. J. (1997). Organizational climate, leadership and individual responses to sexual harassment in the active duty military. Free Inquiry in Creative Sociology 25, pp.1-7.

Firestone, J. M., \& Harris, R. J. (2003). Perceptions of effectiveness of responses to sexual harassment in the U.S. military, 1988 and 1995., Gender, Work and Organization 10, pp.42-64.

Firestone, J. M., \& Harris, R. J. (1994). Sexual harassment in the U.S. military: Individual and environmental contexts. Armed Forces and Society 21, pp.25-43.

Firestone, J. M., \& Harris, R. J. (1999). Changes in patterns of sexual harassment in the U.S. military: A comparison of the 1988 and 1995 DoD Surveys. Armed Forces and Society 25, pp.613-632.

Fitzgerald, L. F., Swan, S., \& Fischer, K. (1995). Why didn't she just report him? The psychological and legal implications of women's responses to sexual harassment. journal of social issues 51, pp.117-138.

Flores-Cervantes, I., Valiant, R.; Harding, L., \& Bell, B. (2003). Weighting for the Status of the Armed Forces Surveys - Workplace and Gender Relations (Form 2002GB). Arlington, VA: Defense Manpower Data Center.

Fowler, F. J., Jr. (2002). Survey Research Methods, $3^{\text {rd }}$ ed. Applied Social Research Methods Series, Vol. 1, Thousand Oaks, CA: Sage.

Giuffre, P. A., \& Williams, C. L. (1994). Boundary lines: Labeling sexual harassment in restaurants. Gender and Society 8, pp.378-401.

Grauerholz, E. (1989). Sexual harassment of women professors by students: Exploring the dynamics of power, authority and gender in a university setting. Sex Roles 21, pp.789-801.

Grauerholz, E. (1996). Sexual harassment in the academy: The case of women professors, In M. S. Stockdale (Ed.), Sexual harassment in the Workplace: Perspectives Frontiers, and Response Strategies, (pp. 29-50). Thousand Oaks, CA: Sage.

Gruber, J. E., \& Bjorn, L. (1986). Women's responses to sexual harassment: An analysis of sociocultural, organizational and personal resource models, Social Science Quarterly 129, pp.814-826. 
Hulin, C. L., Fitzgerald, L. F., and Drasgow, F. (1996). Organizational influences on sexual harassment, In M. S. Stockdale (Ed.), Sexual harassment in the Workplace: Perspectives Frontiers, and Response Strategies (pp. 127-150), Thousand Oaks, CA: Sage.

Kaufman, R. L. (1996). Comparing effects in dichotomous logistic regression: A variety of standardized coefficients. Social Science Quarterly 2, pp.90-109.

Keeter, S., Miller, C., Kohut, A., Groves, R. M., \& Presser, S. (2000). Consequences of reducing non-response in a national telephone survey. Public Opinion Quarterly 64, pp.125-148.

Lipari, R., \& Lancaster, A. R. (2003). Armed Forces 2002 Sexual Harassment Survey. Arlington, VA.: Defense Manpower Data Center.

Livingston, J. A. (1982). Responses to sexual harassment on the job: Legal, organizational, and individual actions. Journal of Social Issues 38, pp. 5-22.

Long, J. S. (1987). A graphical method for the interpretation of multinomial logit analysis. Sociological Methods and Research 15, pp.420-446.

MacKinnon, C. (1979). Sexual Harassment of Working Women. New Haven, CT: Yale University.

Malovich, N. J., \& Stake, J. E. (1990). Sexual harassment on campus: Individual differences in attitudes and beliefs. Psychology of Women Quarterly 14, pp.63-81.

McAllister, B. (1996, March 13). Harassment case took 5 years to resolve. The Washington Post. p. A 19.

Menard, S. (2002). Applied Logistic Regression Analysis, $2^{\text {nd }}$ ed., Quantitative applications in the social sciences, 106, Thousand Oaks, CA: Sage.

Norusis, M. J. (1990). SPSS Advanced Statistics Student Guide. Chicago, IL: SPSS Inc.

Paetzold, R. L., \& O’Leary-Kelly, A. M. (1996). The implications of U.S. Supreme Court and circuit court decisions for hostile environment sexual harassment cases, In M. S. Stockdale (Ed.), Sexual Harassment in the Workplace; Perspectives, Frontiers, and Response Strategies, (pp. 85-104). Thousand Oaks, CA: Sage.

Riger, S. (1991). Gender dilemmas in sexual harassment policies and procedures. American Psychologist 46, pp.497-505.

Saal, F. E. (1996). Men's misperceptions of women's interpersonal behaviors and sexual harassment, In M. S. Stockdale (Ed.), Sexual Harassment in the Workplace; Perspectives, Frontiers, and Response Strategies, (pp.67-84). Thousand Oaks, CA: Sage.

Siegal, D. (1991). Sexual Harassment: Research and Resources. New York: National Council for Research on Women.

Stockdale, M. S., \& Vaux, A. (1993). What sexual harassment experiences lead respondents to acknowledge being sexually harassed? A secondary analysis of a university study, Journal 
of Vocational Behavior 43, pp.221-234.

Tangri, S. S., \& Hayes, S. M. (1997). Theories of sexual harassment, In W. O’Donohue (Ed.). Sexual Harassment, Theory, Research and Treatment, (pp. 112-128). Boston: Allyn and Bacon.

Terpstra, D. E \& Baker, D. D. (1986). A framework for the study of sexual harassment. Basic and Applied Social Psychology 7, pp.17-34.

Thacker, R. A. (1996). A descriptive study of situational and individual influences upon individuals’ responses to sexual harassment, Human Relations 49. pp.1105-1122.

Thomas, M. D. (1995). Gender Differences in Conceptualizing Sexual Harassment. NPRDC-TR-95-5, San Diego, CA: Navy Personnel Research and Development Center.

Welsh, S., \& Gruber, J. E. (1999). Not taking it any more: Women who report or file complaints of sexual harassment. The Canadian Review of Sociology and Anthropology 36, pp.559-583.

Whatley, M. A., \& Wasieleski, D. T. (2001). The incidence of sexual harassment in academia: A pilot study, Radical Pedagogy 3, [Online] Available: http://radicalpedagogy.icaap.org/content/issue3_1/03Whatley.html (June 12, 2007).

Williams, C. L. (1997). Sexual harassment in organizations: A critique of current research and policy. Sexuality and Culture 2, pp.19-43.

\section{Notes}

Note 1 . The $\mathrm{r}$ statistic is a measure of partial correlation, calculated as a transformation of the Wald statistic $[\mathrm{r}=\mathrm{SQRT}((\mathrm{Wald}-2 \mathrm{k}) /-2 \mathrm{LL}(0))$ ]. It is useful for determining the relative importance of the statistically significant variables (Norusis, 1990, p. 48). As is evident in Table 2, however, it does not discriminate among the weaker, non-significant variables, often displaying a value of 0.00 in these cases (see Norusis, 1990).

Note 2. Because the questions used in the 2002 survey were not an exact match to the questions from the original 1988 survey, our conceptualizations for individual and environmental harassment are a broad match, but not an exactly the same as in our earlier research. For a description of the statements classified as individual or environmental harassment, see Firestone and Harris (1994). In this analysis three items are omitted because they refer to sexist contexts that are conceptually distinct from sexual harassment (using derogatory terms, treating differently or putting down people based on gender stereotypes). Note 3. We use Nagelkerke $\mathrm{R}^{2}$ as an indicator of explained variance because Cox and Snell $\mathrm{R}^{2}$ does not always attain a value of 1.0, making comparisons of different models more difficult. 
Appendix A: Calculations of Standardized Logistic Coefficients*

Dependent $=$ Report Through Official Channels

Total

$\begin{array}{llllll}\text { Variable } & \text { b } & \text { sd_x } & \mathbf{R} & \text { sd_logit } & \text { Std_b }\end{array}$

$\begin{array}{llllll}\text { Individualized } & 0.86 & 0.37 & 0.38 & 1.24 & 0.10 \\ \text { Environmental } & 2.02 & 0.43 & 0.38 & 1.24 & 0.27 \\ \text { Labeled } & 1.10 & 0.26 & 0.38 & 1.24 & 0.09\end{array}$

Male

$\begin{array}{llllll}\text { Individualized } & 0.90 & 0.33 & 0.32 & 1.21 & 0.08 \\ \text { Environmental } & 2.37 & 0.41 & 0.32 & 1.21 & 0.26 \\ \text { Labeled } & 0.85 & 0.18 & 0.32 & 1.21 & 0.04\end{array}$

Female

$\begin{array}{llllll}\text { Individualized } & 0.63 & 0.48 & 0.39 & 1.11 & 0.10 \\ \text { Environmental } & 1.08 & 0.50 & 0.39 & 1.11 & 0.19 \\ \text { Labeled } & 1.07 & 0.44 & 0.39 & 1.11 & 0.16\end{array}$

\section{Dependent=Labeled Incident as Harassment}

Total

$\begin{array}{lcclrr}\text { Variable } & \text { b } & \text { sd_x } & \text { R } & \text { sd_logit } & \text { Std_b } \\ \text { Individualized } & 2.34 & 0.37 & 0.34 & 1.79 & 0.16 \\ \text { Environmental } & 2.73 & 0.43 & 0.34 & 1.79 & 0.22\end{array}$

Male

$\begin{array}{llllll}\text { Individualized } & 2.09 & 0.33 & 0.29 & 1.69 & 0.12 \\ \text { Environmental } & 3.04 & 0.41 & 0.29 & 1.69 & 0.21\end{array}$

Female

$\begin{array}{llllll}\text { Individualized } & 2.34 & 0.48 & 0.34 & 1.97 & 0.19 \\ \text { Environmental } & 2.21 & 0.50 & 0.34 & 1.97 & 0.19\end{array}$

Dependent=Individualized Harassment

Total

$\begin{array}{rcrlrr}\text { Variable } & \text { b } & \text { sd_x } & \text { R } & \text { sd_logit } & \text { Std_b } \\ \text { Environmental } & 2.93 & 0.43 & 0.32 & 1.27 & 0.30\end{array}$

Male

$\begin{array}{llllll}\text { Environmental } & 2.82 & 0.41 & 0.29 & 1.15 & 0.29\end{array}$

Female

* Std_b $=(\mathbf{b} *$ sd_X $* \mathbf{R}) /$ sd_logit

Where:

$\mathrm{b}=$ unstandardized logistic coefficient

sd_x = standard deviation of independent variables

$\mathrm{R}=$ correlation of dependent and predicted scores

sd_logit=standard deviation of predicted logit

std_b=standardized logistic coefficient 